Modern Introductions to Philosophy

General Editor: D. J. O'CONNOR

The titles of the volumes in this series are:

MODERN MORAL PHILOSOPHY

W. D. Hudson

THE PHILOSOPHY OF LANGUAGE

Bernard Harrison

POLITICAL PHILOSOPHY

Derek Crabtree

THE LOGIC OF EMPIRICAL ENQUIRY

P. H. Nidditch

AN INTRODUCTION TO THE PHILOSOPHY OF RELIGION

Kai Nielsen

PHILOSOPHY OF HISTORY

R. F. Atkinson

THE THEORY OF KNOWLEDGE

D. W. Hamlyn

MODERN DEDUCTIVE LOGIC

R. J. Ackermann

AESTHETICS

Ruth Saw 
ROBERT J. ACKERMANN is professor of philosophy at the University of Massachusetts. An author of several books, he received his Ph.D. from Michigan State University in 1960. He was a Fulbright Lecturer at the University of Exeter, England, 1964-65; Guggenheim Memorial Foundation Fellow, 1968-69; and has taught at the University of Pennsylvania and Washington University in St. Louis. 


\section{MODERN \\ DEDUCTIVE LOGIC}

An Introduction to Its Techniques and Significance

Robert John Ackermann 
(C) Robert J. Ackermann 1970

All rights reserved. No part of this publication may be reproduced or transmitted, in any form or by any means, without permission.

First published in the United States 1970 First published in the United Kingdom 1970

\author{
Published by \\ MACMILLAN AND CO LTD \\ London and Basingstoke \\ Associated companies in New York Toronto \\ Dublin Melbourne Johannesburg and Madras
}

ISBN 978-0-333-11138-3

ISBN 978-1-349-15396-1 (eBook)

DOI 10.1007/978-1-349-15396-1

The Papermac edition of this book is sold subject to the condition that it shall not, by way of trade or otherwise, be lent, resold, hired out, or otherwise circulated without the publisher's prior consent, in any form of binding or cover other than that in which it is published and without a similar condition including this condition being imposed on the subsequent purchaser. 


\section{Preface}

The general attitude toward the significance of modern deductive logic expressed somewhat implicitly in the text of this book can be stated here in a direct fashion. Modern deductive logic as embodied in standard logical systems is a subtle and ingenious tool for investigating various questions of the soundness of a wide range of mathematical argument, but it is a rather poor and insensitive tool (unless extremely carefully handled) in evaluating the soundness of non-technical argument. In this respect, modern deductive logic differs little from the theory of the syllogism, which preceded it historically. The soundness of syllogisms is very important with respect to a certain style of exposition, and to master material presented in that style, a study of the syllogism is required. But people do not ordinarily argue or think in syllogisms. Similarly, axiomatization of mathematical and some scientific material is the only known method of grounding intelligent discussion of certain foundational problems, and a study of modern deductive logic is required to master the relevant axiomatizations. The problems which the logical systems introduced in this book are ultimately designed to solve are thus simply beyond the grasp of many undergraduates. Predicate Logic, which is in one form or another the second logical system usually introduced to beginning students, is already powerful enough to test the soundness of most of the arguments of modern algebraic theory. There is little wonder that a 
student unfamiliar with the mathematical arguments should be baffled by an instrument ideally suited to testing their soundness.

Apart from its marhematical and scientific applications, one may well wonder whether modern deductive logic has enough philosophical value to assume a major place in the curriculum assigned to philosophy students. Like any fairly precise area of subject matter, logical systems provide a number of intrinsically fascinating technical problems. It is possible to become totally entranced with technical minutiae in the same way that one may become addicted to crossword puzzles. In defense of this preoccupation, one may cite the non-utilitarian tradition of philosophy, if not of pure research. Such a defense, while logically impregnable, often seems to outsiders plainly disingenuous. The importance of logic, and its justification in the philosophy curriculum, seems rather to appear in the realization that logic is often most relevant to philosophical interests precisely where it fails to provide an appropriate assessment of validity. This fact has been somewhat obscured by the arrogance of some practicing logicians in assuming that their current systems should provide the standard for determining whether arguments are sound or defective and inherently confused. Quite often the failure of validity in standard systems points to an interesting way in which the standard systems contain presuppositions which are not appropriately matched in the subject matter of the argument. The existence of precise systems can give such observations a definite form which is useful in trying to give the relevant presuppositions an explicit status. This point of view is well illustrated in the important philosophical perspectives provided by such investigations as [H2] and [P4], listed in Further Reading at the end of this volume. We will consequently take the importance of logic to be directly related to its limitations.

In this book I have attempted to present the standard logical systems of modern logic along with an explicit introduction to the presuppositions embodied in their symbolism. I have tried to make this discussion accessible to beginners without introducing too many falsehoods in the process of 
simplification. The emphasis in modern logic is on rigor, precision, and close attention to detail. Important as these properties are in using logical systems to assess arguments, a careful attempt to exhibit them from the beginning without sufficient informal discussion of why they are invoked can repel students who might be attracted by the purposes which demand these tiresome accompaniments. I have tried to balance discussion of detail against a desire to give the student a sufficiently wide perspective to enable him to decide whether further study of logical systems and their application would prove interesting. Some conventional topics have been entirely omitted. There is, for example, no discussion of "use" and "mention," or of the syllogism. My defense is that these are best avoided rather than hastily dealt with. The distinction between use and mention, for example, is sufficiently given in an English grammar for the kind of argument the student is likely to encounter, and its important connection with such topics as impredicative definitions requires rather advanced discussion of certain mathematical points. An instructor may choose to add particular treatment of truth-tables and of natural deduction rules for direct proof to the general discussion of closely related topics in the text.

An introductory book such as this is obviously dependent on the prior work of a great many people, and is entirely derivative of the material cited in Further Reading except for various pedagogical strategies. In order to avoid submerging the logic in the footnotes, I have avoided careful and expllicit documentation of all of my intellectual debts, a practice which seems in conformity with the style of most introductory texts. Nevertheless, there is a certain residual problem with illustrations and exercises, which are often unavoidably similar in some respects to illustrations and exercises appearing elsewhere. I have consciously adapted one illustrative sentence each from Noam Chomsky, Peter Geach, P. F. Strawson, and Paul Ziff in Chapters 5 and 9. Except for these debts, and those noted in Further Reading, this treatment of modern deductive logic seems sufficiently different to warrant entry into an area nearly saturated with good books. My hope is that 
students and instructors will find the discussions of the nature and difficulties of abstracting from ordinary language to logical symbolism a stimulating introduction to an interesting philosophical problem that is too frequently ignored in logic textbooks.

The exercises considerably augment the material in the chapters, as well as providing necessary drill in manipulatory techniques associated with the symbolism. As a result, it is useful to do the exercises along with reading the text if later chapters are to be comprehensible. Answers are programmed in the following sense. Each exercise directs the reader to a numbered answer at the end of the book. Sometimes the numbered answer will not be a complete answer, but will provide a hint or method of attack to be employed should difficulty be found in working the exercise. Each such hint then directs the reader to another numbered answer, where the solution can be found. Since the numbered answers are correlated with the exercises in a helter-skelter fashion, this structure should considerably facilitate self-study on the part of the student. 


\section{Contents}

Preface

PART ONE: MATHEMATICS AND MODERN LOGIC

1. Abstraction and Appropriateness

2. Arguments and Validity

PART TWO: SENTENTIAL LOGIC

3. Abstracting SL Forms

4. Testing for SL Validity

5. Appropriateness in SL Abstraction

6. Switching Networks

PART THREE: PREDICATE LOGIC

7. Abstracting PL Forms

8. Testing for PL Validity

9. Appropriateness in PL Abstraction

10. Ordering Integers

PART FOUR: FORMAL SYSTEMS

11. Axioms and Machines

12. Logical Systems

13. Theories

Further Reading 